\title{
DEVELOPMENT OF VERBAL CREATIVITY BY BILINGUAL AND ENGLISH AS FOREIGN LANGUAGE LEARNERS IN KINDERGARTEN TO 8TH GRADE SCHOOLS
}

\author{
Nazmiye YEMEZ (1) ${ }^{1 *}$, Kenan DIKILITAŞ (1) ${ }^{2}$ \\ ${ }^{1}$ Institute of Educational Sciences, Department of English Language Teaching, Bahçeşehir University, \\ Çırağan Cad. Osmanpaşa Mektebi Sok. No. 4-6, 34353 Beşiktaş, Istanbul, Turkey \\ ${ }^{2}$ Department of Higher Education Pedagogy, Faculty of Arts and Education, University of Stavanger, \\ Postboks 8600 Forus, 4036 Stavanger, Norway
}

Received 29 April 2020; accepted 14 December 2020

\begin{abstract}
Bilingualism has long been within the scope of creativity studies that investigate creativity and problem solving. This study aims to explore the possible effect of bilingualism on the verbal creativity of English language learners. Participants from a bilingual and an English as foreign language teaching program within the same school were selected as an experimental and a control group respectively to compare verbal creativity. A series of creative English writing tasks designed by the authors were assigned to a total of 86 third grade (aged 7-8) students. Both the English as foreign language group $(\mathrm{N}=42)$ and the bilingual group $(\mathrm{N}=44)$ were subject to assessment and evaluation in terms of verbal creativity. The two cohorts completed the same creative writing tasks that were then assessed by a board of five English teachers from the same school who were trained by the authors to assess verbal creativity using a Student Product Assessment Form. An independent samples Student's $t$-test was conducted and descriptive statistics of both cohorts for 9 of the assessment form were analyzed. The results showed that the students on the bilingual program outperformed those on the English as foreign language program in terms of verbal creativity. The study offers implications for English language teaching in primary schools with reference to developing creative verbal language skills at early ages.
\end{abstract}

Keywords: early bilingualism, convergent thinking, creativity, divergent thinking, verbal creativity.

\section{Introduction}

Bilingual education in Turkish (first language, L1) and English as a foreign language (EFL) (second language, L2) in kindergarten to 12th grade (K-12) schools is supported within the national educational system which aims to educate every Turkish citizen so that he or she can achieve at least "a working knowledge of English" (Karakaş, 2013, p. 167). The key rationale behind this goal is "recognition of the symbolic power of the English language" (Selvi, 2011, p. 196) as well as its role in assisting speakers of the language to find prestigious

^Corresponding author. E-mails: nazmiye.yemez@bahcesehir.edu.tr; nazmis@hotmail.com 
employment opportunities (Doğançay-Aktuna, 1998, p. 34). English is widely accepted as a lingua franca in Turkey and is offered as the principal foreign language in the national curriculum (T.C. Cumhurbaşkanliği mevzuat bilgi sistemi, 2013). However, there are different English programs offered in similar contexts. For instance, private schools offer English lessons starting from kindergarten level. Karakaş (2013, p. 167) argues,

"those attending private schools develop their English far more effectively in terms of specific skills while those in resource-poor environments, at state schools remain less proficient".

Thus, the variety of programs may mainly result from the fact that each program offered is subject to differing financial constraints that ultimately affect delivery and outcome. Parents who are able to afford their child's education within a bilingual system are motivated to invest in their child's participation in bilingual programs on account of the promise of "prestigious jobs" in the future and opt for this system, whereas others may choose EFL-context programs with fewer hours of English instruction. Earlier studies in literature pointed out that bilingual children may show better cognitive development than monolinguals (Bialystok, 2005). Great attention has been drawn to and sustained evidence has been forwarded in support of the philosophy that speaking more than one language extends one's cognitive capacities and creative functioning (Kharkhurin, 2012). In addition, Leikin and Tovli (2014) examined the possible effect of bilingualism on creativity in non-mathematical and mathematical problem solving among bilingual and monolingual preschoolers. The results highlighted the fact that balanced bilingualism has a positive effect on the development of creativity in problem solving; nevertheless, this creativity effect differed according to whether the creativity concerned was fostered in the verbal, general, or mathematical domain. Creativity is an "enhanced normative cognition", which strengthens certain cognitive mechanisms that add to one's creativity (Kharkhurin, 2017). The variance of exposure to English in two different cohorts, that is between bilingual and EFL learners, stimulated the curiosity of the authors and led them to compare the two groups particularly with respect to variance in verbal creativity between the two groups. Although much research has been conducted with regard to monolinguals and bilinguals in terms of their overall creativity (Hommel et al., 2011; Kharkhurin, 2011, 2017; Lee \& Kim, 2010, 2011; Leikin \& Tovli, 2014), relatively little research has been conducted into the development of the verbal creativity of bilingual students, which we will explore in this study. To this end, the study will attempt to formulate responses to the following research questions:

1. Is there a statistically significant difference between EFL and bilingual groups in terms of verbal creativity?

2. If so, how can we differentiate between the two cohorts in terms of verbal creativity?

\section{Literature review}

Early bilingualism implies an ability to deal with two languages, during which several cognitive benefits are also developed (Hommel et al., 2011; Kharkhurin, 2011, 2017; Lee \& Kim, 2010, 2011; Leikin \& Tovli, 2014). One of the benefits described includes creativity, which was defined by van Dijk et al. (2019), as an individual's emerging ability to discover new concepts, 
and to come up with creative ideas and products. Simonton (2008) also defined creativity as the act of generating new ideas or new connections between existing ideas or concepts. These definitions imply that bilingualism leads the bilingual mind to process linguistic-knowledge systems simultaneously and enhance the thinking ability of the individual to act creatively when exposed to complex tasks. Kharkhurin (2011) emphasizes that "selective attention" serves as a contributor to enhanced creative abilities in bilinguals. There were two subconstructs to creativity. One is "innovative capacity"; this refers to the inhibition of irrelevant information, while the other is the facilitation of previous information that can activate "generative capacity". Thus, bilinguals utilize these two mechanisms in employing varying skills to solve problems creatively. The development of creativity within the bilingualism process is associated with the continuous use of executive functioning, which seems to develop more markedly among bilinguals than monolinguals (Hommel et al., 2011; Kharkhurin, 2011; Lee \& Kim, 2010, 2011; Leikin \& Tovli, 2014). Supporting this claim, Kharkhurin (2017) argues that the ability to speak multiple languages may enhance cognitive capacities and strengthen certain cognitive mechanisms, which in turn may influence the potential to be creative.

A number of previous studies report the positive influence of bilingualism on creativity in various contexts. Leikin (2013), for example, shows that children growing up in bilingual families outperform their monolingual peers at creative problem solving. Such benefits are also empirically supported by recent research (e.g., Bialystok, 2001; Leikin, 2013; Leikin \& Tovli, 2014; Simonton, 2008). Okoh (1980) conducted an early study on this topic, investigating verbal creativity in bilingual and monolingual children and found that bilingual children scored higher in verbal-creativity tests than monoglots; however, there was no significant difference in non-verbal creativity tests. Similarly, Leikin and Tovli (2014) examined the effects of bilingualism on creativity. The results indicated that there was a significantly positive effect on the development of creativity in problem solving in cases of balanced bilingualism. Nevertheless, the effect of bilingualism differed across the domains of verbal, general, and mathematical creativity. More recently, Sampedro and Peña (2019) examined performance differences in creativity tasks with respect to the relationship between different levels of bilingualism and school grades among pre-adolescent children from fifth and sixth grades in the Basque Country (autonomous community) (Spain). They found that the high-level group displayed better performances in figural creativity in comparison with the medium and lowlevel groups. Similarly, the high-level group performed more successfully in verbal-creativity tasks compared to the medium-level group. In addition, the school grade provided an effective variable in differences in creativity between the three levels of bilingualism. Moreover, in figural creativity tasks, children from fifth grade enjoyed better results. In a similar vein, Lee and Kim (2010) explored whether a relationship existed between levels of bilingualism and creativity in two subconstructs; these are namely adaptive creative styles and creative strengths. The degree of bilingualism was positively related to both considering the results put forward.

Zhang and Guo (2017) children of immigrant families were perceived as polite, obedient, and passive students lacking creativity and critical-thinking skills but good at rote learning and memorization. However, the research indicated that these children composed poems, created nicknames and homonyms. Their creativity and critical abilities counter the long-held 
perceptions about Chinese learners in western societies. Kharkhurin (2008) also found that Russian-English bilingual immigrants in the United States have greater generative capacity than their monolingual counterparts. Kharkhurin (2009) showed the innovative capacity of Farsi-Iranian bilinguals living in the United Arab Emirates outperformed that of Farsi monolingual speakers residing in Iran. Kharkhurin (2011) also showed that more linguistically advanced bilinguals performed better in terms of innovative capacity in creative problem solving than their monolingual counterparts.

Kharkhurin and Wei (2015) examined the effect of selective attention in bilingual creative performance in "code switching"; that is shifting from one language to another during the same episode of speech production. Bilinguals who code switch frequently revealed a greater innovative capacity than those who did not employ the technique in their daily conversations. Creative capacity was further examined by Kharkhurin and Wei (2015) to explore the effect of this emotion-triggered code "switching on" creativity. The role of positive emotions within the bilingual non-verbal creativity process among Arabic-English bilingual college students was reported to be evoked positively in English tests, but negatively in Arabic texts.

Consequently, a myriad of studies has dealt with the effect of bilingualism on creativity whereas none has focused on the effect of different English teaching programs on creativity within the same context. Thus, we will be considering the latter in more detail.

\section{Methodology}

This study aims to explore whether creativity differs between the two separate English learning programs of a 3rd grade program of a private school. A quasi-experimental research design was used to compare the verbal creativity in 3rd grade EFL and bilingual programs at the same private school. A creative writing task (Appendix 1) was developed by five faculty members to assess the verbal creativity of 3rd grade learners. To evaluate verbal creativity, Item 9 of the overall Student Assessment Product Form (SPAF) (Morgan Reis, 1981) was used. An independent samples Student's $t$-test was conducted for the 6 items of the scale to explore if there was a statistically significant difference in verbal creativity between the two cohorts.

\subsection{Setting and participants}

In Turkey, the majority of early K-12 schools' students can be identified as consecutive or successive bilinguals (Lambert, 1972) who begin to acquire English as a foreign language at age 4 in K-12 schools. Participants of the present study were students in grade 3 (8-9 years of age) at a private $\mathrm{K}-12$ chain school in Turkey. In terms of the forms of bilingualism they had experienced, according to Lambert (1972), learners in both groups had already partially acquired Turkish as L1 and then learned English as a L2 in their early childhood. Hence, they were all consecutive (or successive) bilinguals and since their first exposure to English had taken place at kindergarten (age 4-5), they may be considered as early bilinguals.

At this particular school, there were two different English programs. In both programs, English was the foreign language offered within the school curriculum. The first program 
described as "bilingual" was based on a co-teaching system, where both an L1 and L2 teacher co-existed in class in mathematics (2 lessons), science (2 lessons), and social sciences (1 lesson). The break-down of the English program was as follows: a total of 8 lessons: $5=$ integrated skills: listening, speaking, reading, writing, 3 = project and presentation skills. There was a total of 16 English lessons per week. The native-speaker teacher spoke in only L1 to teach subjects in social sciences, mathematics, and science. The L2 teacher (non-native speaker of English) spoke only in L2 to teach the corresponding subjects of the syllabus in L1. On the other hand, the second program, EFL, encompassed a mainstream approach which had 10 lessons of English per week, 6 lessons of which involved the integrated teaching of the four principal language skills, namely reading, writing, listening, and speaking, and 4 lessons of project and presentation skills in English delivered by a non-native speaker of English. The homeroom teacher taught L1, mathematics (L1), and science (L1) in the designated periods in the EFL group. The total number of student participants was 86, 44 of which were from the bilingual cohort and 42 which originated from the EFL cohort. The two programs were administered at two branches of the same K12 private chain school, only at different campuses of Istanbul, Turkey. However, both programs served students of a similar socioeconomic family-background students in terms of grade, age, and English level. In addition, a board of five English teacher-judges evaluated the assigned creative task after receiving a one-hour assessment training session to benchmark the effectiveness of their evaluation.

\subsection{Instrumentation}

There were two research tools used in this study. The first was a creative writing task adapted from Education.com (2020b) by the authors (Appendix 1) which was developed in cooperation with the teachers of the students at the same school. Prompts were discussed in order to enhance convergent and, more specifically, divergent thinking skills. The creative writing task was prepared, edited, and proofread by the English teachers of the same faculty. The task was constructed around the identity of an imaginary pet dinosaur. Students were asked to name, describe, and feed it according to their own areas of interest. Each student was then encouraged to imagine and describe the dinosaur's favorite food and explain the activities that he or she would like to do with this dinosaur. Then, on the second page of the task, students were asked to imagine a day out with their pet dinosaur. On this section of the task, students filled in the spaces of a guided day with descriptions of the objects, people, and events that they encountered with their pet dinosaur.

The second instrument used was to evaluate verbal creativity. Item 9 of the overall SPAF (Morgan Reis, 1981) with items from A-G was used. Item 9 consisted of 7 sub-items: (A originality of the idea, B - achieved objectives stated in plan, $\mathrm{C}$ - advanced familiarity with subject, D - quality beyond age/grade level, E - care, attention to detail, etc., F - time, effort, and energy, G - originality contribution) which offered a 5-point Likert scale consisting of five values: " 1 = poor, 2 = below average, 3 = average, $4=$ above average, $5=$ outstanding". An independent samples Student's $t$-test was conducted to compare the mean values of the two groups using Microsoft Excel. 


\subsection{Procedures and analysis}

The creative-writing task (Appendix 1) was prepared by the authors to be administered to the participants. Official permission was received from the school principals of the two different branches of the K-12 private chain school. The English teachers of the two cohorts were consulted to prepare, edit, and proofread the writing task. The creative writing task was administered to students in two successive lessons on the same day. After the activities were conducted, the task worksheets were assigned to the authors of the study.

Upon reception of the package of completed worksheets, a panel of five English teachers evaluated the creative-writing task worksheets using SPAF. Before the evaluation started, the judges were offered a benchmarking training session which lasted 40 minutes employing a workshop format. The 5-point Likert scale and a number of sample student task worksheets were used to benchmark the evaluation unanimously among the group of judges. The results were then analyzed by the authors via an independent samples Student's $t$-test.

\subsection{Results}

To answer the first research question, an independent-samples Student's $t$-test was conducted to compare verbal creativity for EFL and the bilingual conditions for a creative writing task. A significant difference was identified in the scores for $\mathrm{EFL}(\mathrm{M}=2.03, \mathrm{SD}=1.14)$ and bilingual $(\mathrm{M}=3.19, \mathrm{SD}=1.23)$ conditions; $\mathrm{t}(8)=1.85, \mathrm{p}=.006$. These results suggest that bilingualism does indeed have a tangible effect on verbal creativity in creative writing. Specifically, our results suggested that the bilingual group outperformed the EFL group in verbal creativity in the given creative writing task.

When the means of EFL and bilingual groups were calculated, the results showed that in all scale items, namely A - originality of the idea, B - achieved objectives stated in plan, $\mathrm{C}$ - advanced familiarity with subject, D - quality beyond age/grade level, E - care, attention to detail, etc., F - time, effort, and energy, G - originality contribution, the bilingual group participants enjoyed higher mean values than those of the EFL group. Tables 1-7 below compare the responses of the participants to each scale item (A-G).

Originality of the idea item (EFL: $\mathrm{M}=2.36, \mathrm{SD}=1.14$; $\mathrm{BIL}: \mathrm{M}=3.30, \mathrm{SD}=1.23$ ) illustrates that students in the bilingual group possessed more divergent thinking skills than their peers in the EFL group (Table 1). Divergent thinking in form of fluency, flexibility, elaboration, and originality in responses to the task refer to their ability to produce original ideas.

Achieved objectives stated in plan item (EFL: $\mathrm{M}=2.12$, $\mathrm{SD}=1.17$; BIL: $\mathrm{M}=3.27$, $\mathrm{SD}=1.29$ ) shows that bilingual group achieved objectives more successfully than their counterparts in EFL group (Table 2). This item sought sound statements from the participants that showed complete understanding of the objectives in the task.

Table 1. Descriptive statistics of the scale items A - originality of the idea for English as foreign language (EFL) and bilingual (BIL) groups (source: created by authors)

\begin{tabular}{|l|c|c|c|c|c|c|c|c|c|c|}
\hline Responses & $N$ & $M$ & $S D$ & Median & SEM & Skewness & Kurtosis & Min & Max & Total \\
\hline EFL & 42 & 2.36 & 1.14 & 2.00 & 0.18 & 0.47 & -0.83 & 1 & 5 & 99 \\
\hline BIL & 44 & 3.30 & 1.23 & 3.00 & 0.19 & -0.05 & -0.95 & 1 & 5 & 145 \\
\hline
\end{tabular}


Table 2. Descriptive statistics of the scale items B - achieved objectives stated in the plan for English as foreign language (EFL) and bilingual (BIL) groups (source: created by authors)

\begin{tabular}{|l|c|c|c|c|c|c|c|c|c|c|}
\hline Responses & $N$ & $M$ & $S D$ & Median & SEM & Skewness & Kurtosis & Min & Max & Total \\
\hline EFL & 42 & 2.12 & 1,17 & 2.00 & 0.18 & 0.81 & -0.49 & 1 & 5 & 89 \\
\hline BIL & 44 & 3.27 & 1.39 & 3.00 & 0.21 & -0.02 & -1.37 & 1 & 5 & 144 \\
\hline
\end{tabular}

In parallel, the advanced familiarity with subject item (EFL: $\mathrm{M}=2.02, \mathrm{SD}=1.16$; BIL: $\mathrm{M}=3.18, \mathrm{SD}=1.33$ ) indicated that the bilingual cohort outperformed the EFL group with regard to their superior adaptation to the subject (Table 3). The more familiar the participant found himself with regard to the subject, the better and quicker enhancement of cognitive skills were observed.

Table 3. Descriptive statistics of the scale items C - advanced familiarity with subject for English as foreign language (EFL) and bilingual (BIL) groups (source: created by authors)

\begin{tabular}{|l|c|c|c|c|c|c|c|c|c|c|}
\hline Responses & $N$ & $M$ & $S D$ & Median & SEM & Skewness & Kurtosis & Min & Max & Total \\
\hline EFL & 42 & 2.02 & 1.16 & 2.00 & 0.18 & 0.94 & -0.20 & 1 & 5 & 85 \\
\hline BIL & 44 & 3.18 & 1.33 & 3.00 & 0.20 & 0.08 & -1.22 & 1 & 5 & 140 \\
\hline
\end{tabular}

The quality beyond age/grade level item similarly produced more creative responses for the bilingual group than the EFL group ( $E F L: M=2.02, S D=1.02 ; B I L: M=3.05, S D=1.22$ ) (Table 4). This item simply illustrated the feeling of eccentricity with regard to the achievement of the response.

Table 4. Descriptive statistics of the scale items D - quality beyond age/grade level for English as foreign language (EFL) and bilingual (BIL) groups (source: created by authors)

\begin{tabular}{|l|c|c|c|c|c|c|c|c|c|c|}
\hline Responses & $N$ & $M$ & SD & Median & SEM & Skewness & Kurtosis & Min & Max & Total \\
\hline EFL & 42 & 2.02 & 1.02 & 2.00 & 0.16 & 0.95 & 0.55 & 1 & 5 & 85 \\
\hline BIL & 44 & 3.05 & 1.22 & 3.00 & 0.18 & 0.15 & -1.17 & 1 & 5 & 134 \\
\hline
\end{tabular}

The care, attention to detail, etc. item showed the following results: (EFL: $M=2.00, S D=$ 0 ; BIL: $\mathrm{M}=3.14, \mathrm{SD}=1.30$ ) (Table 5). In other words, EFL responses received a (2) from all 5 judges which corresponded to "below average". When an intriguing item on the scale for the EFL cohort was identified, the task was then subject to careful analysis and thoughtful consideration before the response was composed on paper.

Table 5. Descriptive statistics of the scale items E - care, attention to detail, etc. for English as foreign language (EFL) and bilingual (BIL) groups (source: created by authors)

\begin{tabular}{|l|c|c|c|c|c|c|c|c|c|c|}
\hline Responses & $N$ & $M$ & $S D$ & Median & SEM & Skewness & Kurtosis & Min & Max & Total \\
\hline EFL & 42 & 2.00 & 0 & 2.00 & 0 & 0 & 0 & 2 & 2 & 84 \\
\hline BIL & 44 & 3.14 & 1.30 & 3.00 & 0.20 & 0.13 & -1.12 & 1 & 5 & 138 \\
\hline
\end{tabular}


The time, effort, and energy item also suggested that students in the bilingual group put more effort into the given tasks than the students in the EFL group (EFL: $\mathrm{M}=2.05, \mathrm{SD}=$ 1.19; BIL: $\mathrm{M}=3.23, \mathrm{SD}=1.33$ ) (Table 6). This item measured the learners' resilience towards dealing with the task.

Table 6. Descriptive statistics of the scale items F - time, effort, and energy for English as foreign language (EFL) and bilingual (BIL) groups (source: created by authors)

\begin{tabular}{|l|c|c|c|c|c|c|c|c|c|c|}
\hline Responses & $N$ & $M$ & SD & Median & SEM & Skewness & Kurtosis & Min & Max & Total \\
\hline EFL & 42 & 2.05 & 1.19 & 2.00 & 0.18 & 0.82 & -0.53 & 1 & 5 & 86 \\
\hline BIL & 44 & 3.23 & 1.33 & 3.00 & 0.20 & 0 & -1.20 & 1 & 5 & 142 \\
\hline
\end{tabular}

Last but not the least, originality contribution item registered the biggest difference in means/mean values between the two groups: (EFL: $\mathrm{M}=1.95, \mathrm{SD}=1.03$; $\mathrm{BIL}: \mathrm{M}=3.32, \mathrm{SD}=$ 1.29) (Table 7). Furthermore, bilingual participants achieved better scores in item 7 as well. A variety of choices in the responses that displayed verbal creativity were measured with regard to the item.

Table 7. Descriptive statistics of the scale items G - originality contribution for English as foreign language (EFL) and bilingual (BIL) groups (source: created by authors)

\begin{tabular}{|l|c|c|c|c|c|c|c|c|c|c|}
\hline Responses & $N$ & $M$ & SD & Median & SEM & Skewness & Kurtosis & Min & Max & Total \\
\hline EFL & 42 & 1,95 & 1.03 & 2.00 & 0.16 & 0.79 & -0.53 & 1 & 4 & 82 \\
\hline BIL & 44 & 3.32 & 1.29 & 3.00 & 0.19 & -0.22 & -1.05 & 1 & 5 & 146 \\
\hline
\end{tabular}

To answer the second research question about how we can differentiate verbal creativity between the two bilingual cohorts, we selected some descriptions (Table 8) whose responses were evaluated and assigned highest and lowest score in response to the prompt: What does it (the pet dinosaur) look like?

Table 8. Sample assessment of the responses from English as foreign language (EFL) and bilingual (BIL) groups (source: created by authors)

\begin{tabular}{|l|l|c|}
\hline \multicolumn{1}{|c|}{ Participants } & \multicolumn{1}{c|}{ Responses } & Scores \\
\hline EFL16 & Like feed. & 1 \\
\hline EFL15 & It is long. & 1 \\
\hline EFL12 & It looks like. & 1 \\
\hline EFL39 & Big. & 1 \\
\hline BIL13 & It is shiny white. & 5 \\
\hline BIL8 & It has small tail, little spots and big eyes. & 5 \\
\hline BIL7 & It has big eyes. & 4 \\
\hline BIL1 & It has cute eyes. It is furry and its purple fur is shiny like a star. & 5 \\
\hline
\end{tabular}

In the responses of EFL and bilingual students alike, the measures clearly credited verbal creativity with regard to the originality of the idea, the achieved objectives stated in the 
plan, advanced familiarity with the subject, quality beyond age or grade level, care, attention to detail, etc., time, effort, and energy, and originality of the contribution. Having seen the differences in terms of number of the words to the responses (i.e. EFL16: 2 words, BIL8: 9 words), the use of more sophisticated descriptive adjectives (i.e. EFL12: no use of adjectives, BIL8: use of three descriptive adjectives - "small", "little", "big" and similes (i.e. BIL1: "shiny like a star") between the two groups, we took the samples of the highest score (5 = outstanding) responses from both groups in Table 9 below to see how we can differentiate verbal creativity between the two cohorts.

Table 9. Number of the highest-scoring ( $5=$ outstanding) students according to creativity sub-constructs and their sample responses (English as foreign language - EFL, bilingual - BIL) (source: created by authors)

\begin{tabular}{|l|l|}
\hline \multicolumn{1}{|c|}{$\begin{array}{c}\text { Sub-construct of the } \\
\text { creativity scale }\end{array}$} & \multicolumn{1}{c|}{ Sample responses from each group } \\
\hline $\begin{array}{l}\text { Originality of the idea } \\
1 \text { EFL - 10 BIL }\end{array}$ & $\begin{array}{l}\text { It has got neon tones and she is soo (!) happy } \\
\text { (EFL7). } \\
\text { We see colorful butterflies. The butterflies are } \\
\text { dancing (BIL26). }\end{array}$ \\
\hline $\begin{array}{l}\text { Achieved objectives stated in plan } \\
1 \text { EFL - 13 BIL }\end{array}$ & $\begin{array}{l}\text { Finally, we go my home and we read books and do house } \\
\text { activities (EFL7). } \\
\text { Finally, I go to the park and I look at Pamuk and I take Pamuk } \\
\text { and I go to the home (BIL13). }\end{array}$ \\
\hline $\begin{array}{l}\text { Advanced familiarity with subject } \\
1 \text { EFL - 10 BIL }\end{array}$ & $\begin{array}{l}\text { We play there and we eat ice cream (EFL7). } \\
\text { Then I look at tree. 1 second I look at Pamuk. Pamuk is not } \\
\text { there. Again and again, I look for Pamuk but Pamuk disappears } \\
\text { (BIL13). }\end{array}$ \\
\hline $\begin{array}{l}\text { Quality beyond age/grade level } \\
1 \text { EFL - 4 BIL }\end{array}$ & $\begin{array}{l}\text { It has got neon tones and she is soo (!) happy (EFL7). } \\
\text { It has cute eyes, It is furry and its purple fur is shiny like a star } \\
\text { (BIL1). }\end{array}$ \\
\hline $\begin{array}{l}\text { Care, attention to detail, etc. } \\
0 \text { EFL - 9 BIL }\end{array}$ & $\begin{array}{l}\text { None (EFL). } \\
\text { I feed my pet like I put my pet's food on my hand and my pet is } \\
\text { eat (BIL1). }\end{array}$ \\
\hline $\begin{array}{l}\text { Time, effort, and energy } \\
1 \text { EFL - 10 BIL }\end{array}$ & $\begin{array}{l}\text { Elaborately and carefully hand-written responses accompanied } \\
\text { with colorful drawings received a "5". }\end{array}$ \\
\hline $\begin{array}{l}\text { Originality contribution } \\
0 \text { EFL - 10 BIL }\end{array}$ & $\begin{array}{l}\text { None (EFL). } \\
\text { There are two energy waters. Mikel Jordan and I go to the } \\
\text { market (BIL7). }\end{array}$ \\
\hline
\end{tabular}

The variance of frequency among the highest scorers in the sub-constructs as illustrated in Table 9 manifests a notable difference in the number of highest scorers in each group. The number of the students who received the highest evaluations in the subconstructs of creativity is constantly higher in the following categories: originality of the idea $-1 \mathrm{EFL}-10 \mathrm{BIL}$, achieved objectives stated in plan - 1 EFL - 13 BIL, advanced familiarity with subject $1 \mathrm{EFL}-10 \mathrm{BIL}$, quality beyond age/grade level - $1 \mathrm{EFL}-4 \mathrm{BIL}$ care, attention to detail, etc. 0 EFL - 9 BIL, time, effort, and energy - 1 EFL - 10 BIL, originality contribution - 0 EFL $10 \mathrm{BIL}$. These results substantiate the fact that the written products of the bilingual cohort showed a greater variety of creativity in the task. 


\section{Discussion}

We will now discuss our findings to address our two research questions drawing on the results from the qualitative and quantitively data.

- RQ1. Is there a statistically significant difference between EFL and bilingual groups in terms of verbal creativity?

The existing empirical studies demonstrate that individuals who speak more than one language enjoy a predominant advantage over their monolingual counterparts in various creativity tests such as those devised by Hommel et al. (2011), Kharkhurin (2011, 2017), Lee and Kim (2010, 2011), and Leikin and Tovli (2014). However, our study aimed to explore a significant difference, not between monolinguals and bilinguals, but between two bilingual cohorts that employ different approaches in similar successive bilingual contexts. This is where we can claim that using the above-mentioned studies as our starting point, creativity in verbal production in different bilingual programs can be investigated to ascertain the advantages of one bilingual program over another. The findings showed that originality contribution extended the furthest between the groups than among the other sub-constructs of verbal creativity. The literature generally supports the hypothesis regarding a positive correlation between bilingualism and creativity (Adesope et al., 2010; Ricciardelli, 1992; Simonton, 2008); bilinguals score higher than monolinguals on verbal originality and flexibility and on figural originality and fluency (Simonton, 2008). However, Kharkhurin (2010), in a bilingual context found significant differences between non-verbal and verbal creativity. Bilingualism was shown to have a positive effect on non-verbal creative behavior, but monolinguals were found to be better than bilinguals on verbal creativity measures. Simonton (2008) also referred to some methodological and theoretical reasons in order to investigate the association between bilingualism and creativity. Both creativity and bilingualism are two complex issues that can be influenced with respect to varying circumstances like L2 proficiency, age, and cultural context (Adesope et al., 2010; Leikin, 2013; Ricciardelli, 1992) and they illustrate positive correlation between creativity and proficiency in L1 and L2.

As there have been some contradictions in the field of monolingual vs. bilingual research, our findings suggest that there is a significant difference in verbal creativity between two bilingual groups in a similar context. The finding can provide a complementary result to the studies of Leikin and Tovli (2014) which examined the possible effects of bilingualism on creativity in both non-mathematical and mathematical problem solving among bilingual and monolingual preschoolers. Furthermore, the approach that speaking more than one language extends one's cognitive capacities in favor of developing specific architectures of the mind via bilingualism (Bialystok, 2005) is in parallel with our findings. Such specific architecture offers cognitive advantages,

"ideas and tangible products that are novel and useful are assumed to emerge from the application of ordinary, fundamental cognitive processes to existing knowledge structures" (Ward, 2007, p. 28).

Creative cognition, a product of normative cognitive functioning with novelty in nature and appropriateness can manifest itself in our study as we found that a bilingual with higher originality contribution can write in a more unanticipated way with useful ideas. This phenomenon was also suggested by Mayer (1999). We discuss this in the second question. 
- RQ2. If so, how can we differentiate between the two cohorts in terms of verbal creativity?

To address the second question, we selected some sample responses that were evaluated with the highest and lowest scores to the prompts in the creative writing task (Appendix 1). To what extent and intensity verbal creativity can be realized was our concern. A greater number of words in statements, the use of elaborate descriptive adjectives, and a larger volume of content words, function words, and similes (metaphorical imagery) are evidence of verbal creativity. Simonton (2008) defined the act of generating new ideas or new connections between existing ideas or concepts as creativity. For instance, B1's response "It has cute eyes. It is furry and its purple fur is shiny like a star" demonstrates parallel findings to Kharkhurin (2011) which emphasizes the "selective attention" that contributes to enhanced creative abilities in bilinguals. How bilingualism leads the bilingual mind to process linguistic knowledge systems simultaneously and influence one's thinking ability to act creatively when exposed to complex tasks. B1's use of the descriptive adjective "furry", "shiny", and the simile "shiny like a star". Similarly, B13's “Then I look at tree. 1 second I look at Pamuk (pet's given name). Pamuk is not there. Again and again, I look for Pamuk but Pamuk disappears" is a token of both the "generative" and "innovative" capacity that empowers bilinguals to utilize these two mechanisms (Kharkhurin, 2011). Lee and Kim (2010), Lasagabaster (2000) and Ricciardelli (1992) further indicate that the degree of bilingualism is positively associated with creativity. This is consistent with previous studies which demonstrate that bilingual children tend to be more creative than monolinguals. In the same vein, B1's "I feed my pet like I put my pets food on my hand and my pet is eat" implies an adaptive creative style and strength associated with creativity, which is in parallel with Lee's and Kim's (2010) exploration of a relationship between levels of bilingualism and creativity.

In our findings, the bilingual program also seems to initiate both divergent and convergent thinking cycles to generate new and alternative solutions which reflect much convergence with the findings and views of Guilford (1967) on this issue. Convergent thinking is a conscious, attention-demanding process, whereas divergent thinking is unconscious, attention-defocused, and associative. The results of the bilingual group indicate the ability to produce solutions to a problem rapidly and consider many approaches simultaneously that they can carry out more effectively than EFL students. Both convergent and divergent thinking skills in our findings are manifested. According to Guilford (1967), creative thinking is the ability to initiate both divergent and convergent thinking cycles which pave the way to generate new and alternative solutions. The selection of descriptive words such as "neon", "soo (!)", and "Mikel Jordan" as the pet's given name depict what Guilford (1967) asserts as the four characteristics of divergent thinking: namely fluency, flexibility, elaboration, and originality. Selection of "neon" instead of an ordinary yellow or blue, the use of the extra "o" in "soo (!)" with an exclamation mark in parentheses and associating a pet dinosaur with a basketball celebrity "Michael Jordan" offer tangible evidential examples of divergent and convergent thinking cycles with regard to creative thinking ability. Overall, our study seems to have identified and confirmed the effectiveness of one of the principal goals of bilingual education, namely the empowerment of bilinguals to use their entire language repertoire in different situations for added criticality and creativity (Wei, 2011). 


\section{Implications}

This research offers practical implications for language teachers, early schooling program coordinators, and curriculum designers. The significantly higher creativity performance of the bilingual group compared to the EFL learners implies that bilingual education may support the development of verbal creativity closely related to the creative expression of meanings even at early ages. We suggest that an instructional model that embeds a creativity aspect might encourage children to become creative users of language, thus enhancing their bilingual abilities. Creative writing can therefore not only promote language use, but also is promoted by bilingual learning experiences in the classroom.

\section{Limitations}

We need to emphasize that the scope of the research particularly aimed to explore verbal creativity rather than L2 competency, efficiency, fluency, and proficiency. What we strove for as our principal objective was to dig more deeply into aspects of subtle verbal creativity through a creative writing task evaluated with the aid of a Item 9 creativity scale by a panel of judges. We also focused on grade 3 students and conducted only one task with them. In further research, this study can be replicated in a longitudinal version, looking at results in comparison with improvements of verbal creativity throughout a whole academic year with multiple measurements.

\section{Conclusions}

To the authors of this article, assessing and evaluating verbal creativity in written problemsolving tasks within the scope of language learning and teaching practice accrued the possible effect of bilingualism on the verbal creativity of English language learners. Amidst different English programs offered in similar contexts, participants from a bilingual and an English as foreign language teaching program within the same chain school construed an opportunity to the authors to compare verbal creativity in identical language programs. Writing tasks designed by the authors advocated for possible verbal creativity outcomes. The results attested that different language learning programs may have varying impact on learners' verbal creativity. Hence, implications for English language teaching in primary schools with reference to developing creative verbal language skills at early ages can be attained. The variety of language learning programs emerging from varying financial constraints seems to ultimately affect delivery and outcome. Thus, the stakeholders of foreign language education need to be aware about the conspicuous outcome and invest in their young generations' foreign language learning needs accordingly in EFL-context programs.

\section{References}

Adesope, O. O., Lavin, T., Thompson, T., \& Ungerleider, Ch. (2010). A systematic review and metaanalysis of the cognitive correlates of bilingualism. Review of Educational Research, 80(2), 207-245. https://doi.org/10.3102/0034654310368803

Bialystok, E. (2001). Bilingualism in development: Language, literacy, and cognition. Cambridge University Press. https://doi.org/10.1017/CBO9780511605963 
Bialystok, E. (2005). Consequences of bilingualism for cognitive development. In J. F. Kroll \& A. M. B. de Groot (Eds.), Handbook of bilingualism: Psycholinguistic approaches (pp. 417-432). Oxford University Press, Inc.

Dijk, van M., Kroesbergen, E. H., Blom, E., \& Leseman, P. P. M. (2019). Bilingualism and creativity: Towards a situated cognition approach. Journal of Creative Behavior, 53(2), 178-188. https://doi.org/10.1002/jocb.238

Doğançay-Aktuna, S. (1998). The spread of English in Turkey and its current sociolinguistic profile. Journal of Multilingual and Multicultural Development, 19(1), 23-39. https://doi.org/10.1080/01434639808666340

Education.com. (2020a). Creative writing for kids: Pet dinosaur. https://www.education.com/worksheet/ article/creative-writing-for-kids-10/

Education.com. (2020b). Free worksheets and printables for kids. https://www.education.com/worksheets/ Guilford, J. P. (1967). McGraw-Hill series in psychology. The nature of human intelligence. McGraw-Hill.

Hommel, B., Colzato, L. S., Fischer, R., \& Christoffels, I. K. (2011). Bilingualism and creativity: Benefits in convergent thinking come with losses in divergent thinking. Frontiers in Psychology, 2. https://doi.org/10.3389/fpsyg.2011.00273

Karakaş, A. (2013). The expansion of the English language across Turkey: Threat or opportunity? Mediterranean Journal of Humanities, 3(2), 159-171. https://doi.org/10.13114/MJH/201322477

Kharkhurin, A. V. (2010). Bilingual verbal and nonverbal creative behavior. International Journal of Bilingualism, 14(2), 211-226. https://doi.org/10.1177/1367006910363060

Kharkhurin, A. V. (2017). Bilingualism and creativity: An educational perspective. In W. E. Wright, S. Boun, \& O. García (Eds.). The handbook of bilingual and multilingual education (pp. 38-55). John Wiley \& Sons, Inc. https://doi.org/10.1002/9781118533406.ch3

Kharkhurin, A. V. (2012). Bilingual education and bilingualism. Multilingualism and creativity. N. H. Hornberger (Series Ed.). Multilingual Matters.

Kharkhurin, A. V. (2008). The effects of linguistic proficiency, age of second language acquisition, and length of exposure to a new cultural environment on bilinguals' divergent thinking. Bilingualism: Language and Cognition, 11(2), 225-243. https://doi.org/10.1017/S1366728908003398

Kharkhurin, A. V. (2009). The role of bilingualism in creative performance on divergent thinking and invented alien creatures tests. Journal of Creative Behavior, 43(1), 59-71. https://doi.org/10.1002/j.2162-6057.2009.tb01306.x

Kharkhurin, A. V. (2011). The role of selective attention in bilingual creativity. Creativity Research Journal, 23(3), 239-254. https://doi.org/10.1080/10400419.2011.595979

Kharkhurin, A. V., \& Wei, L. (2015). The role of code-switching in bilingual creativity. International Journal of Bilingual Education and Bilingualism, 18(2), 153-169. https://doi.org/10.1080/13670050.2014.884211

Lambert, W. E. (1972). Studies in bilingual education. Bilingual education of children: The St. Lambert experiment. Newbury House Publishers.

Lasagabaster, D. (2000). The effects of three bilingual education models on linguistic creativity. International Review of Applied Linguistics in Language Teaching, 38(3-4), 213-228. https://doi.org/10.1515/iral.2000.38.3-4.213

Lee, H., \& Kim, K. H. (2011). Can speaking more languages enhance your creativity? Relationship between bilingualism and creative potential among Korean American students with multicultural link. Personality and Individual Differences, 50(8), 1186-1190. https://doi.org/10.1016/j.paid.2011.01.039

Lee, H., \& Kim, K. H. (2010). Relationships between bilingualism and adaptive creative style, innovative creative style, and creative strengths among Korean American students. Creativity Research Journal, 22(4), 402-407. https://doi.org/10.1080/10400419.2010.523409 
Leikin, M. (2013). The effect of bilingualism on creativity: Developmental and educational perspectives. International Journal of Bilingualism, 17(4), 431-447. https://doi.org/10.1177/1367006912438300

Leikin, M., \& Tovli, E. (2014). Bilingualism and creativity in early childhood. Creativity Research Journal, 26(4), 411-417. https://doi.org/10.1080/10400419.2014.961779

Mayer, R. E. (1999). Fifty years of creativity research. In R. J. Sternberg (Ed.), Handbook of creativity (pp. 449-460). Cambridge University Press. https://doi.org/10.1017/CBO9780511807916.024

Morgan Reis, S. (1981). An analysis of the productivity of gifted students participating in programs using the revolving door identification model [ $\mathrm{PhD} /$ Doctoral Thesis, University of Connecticut]. Storrs, Connecticut, United States [unpublished source].

Okoh, N. (1980). Bilingualism and divergent thinking among Nigerian and Welsh school children. The Journal of Social Psychology, 110(2), 163-170. https://doi.org/10.1080/00224545.1980.9924242

Ricciardelli, L. A. (1992). Bilingualism and cognitive development: A review of past and recent findings. Journal of Creative Behavior, 26, 242-254. https://doi.org/10.1002/j.2162-6057.1992.tb01183.x

Sampedro, A., \& Peña, J. (2019). The effect of bilingualism level on creative performance during preadolescent period. The Spanish Journal of Psychology, 22, E12. https://doi.org/10.1017/sjp.2019.17

Selvi, A. F. (2011). World Englishes in the Turkish sociolinguistic context. World Englishes, 30(2), 182199. https://doi.org/10.1111/j.1467-971X.2011.01705.x

Simonton, D. K. (2008). Bilingualism and creativity. In J. Altarriba \& R. R. Heredia (Eds.), An introduction to bilingualism: Principles and processes (pp. 147-166). Lawrence Erlbaum Associates.

T.C. Cumhurbaşkanliği mevzuat bilgi sistemi. (2013). Millî eğitim bakanliği ortaöğretim kurumlari yönetmeliği. Resmî Gazete Tarihi: 07.09.2013. Resmî Gazete Sayıs1: 28758. https://www.mevzuat. gov.tr/mevzuat?MevzuatNo=18812\&MevzuatTur=7\&MevzuatTertip=5

Ward, Th. B. (2007). Creative cognition as a window on creativity. Methods, 42(1), 28-37. https://doi.org/10.1016/j.ymeth.2006.12.002

Wei, L. (2011). Moment analysis and translanguaging space: Discursive construction of identities by multilingual Chinese Youth in Britain. Journal of Pragmatics, 43(5), 1222-1235. https://doi.org/10.1016/j.pragma.2010.07.035

Zhang, Y., \& Guo, Y. (2017). Exceeding boundaries: Chinese children's playful use of languages in their literacy practices in a Mandarin-English bilingual program. International Journal of Bilingual Education and Bilingualism, 20(1), 52-68. https://doi.org/10.1080/13670050.2015.1037713

\section{Appendix 1.}

Creative writing task (source: created by authors with the adaptation of Education.com, 2020a)

\section{MEET MY PET DINOSAUR!}

- Imagine you have a pet dinosaur.

What is its name?

What color is it?

Is it big or small?

What does it look like?
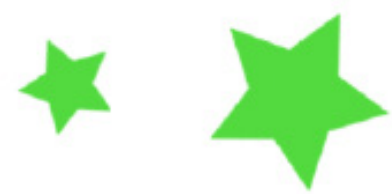
How do you feed it?

What is its favorite food?

What do you like doing with it?

Imagine you have a day out with and I go to the park one day. We

There are

There is also

All of a sudden,

I feel

because

Then I

Later,

looks

feels

Finally,

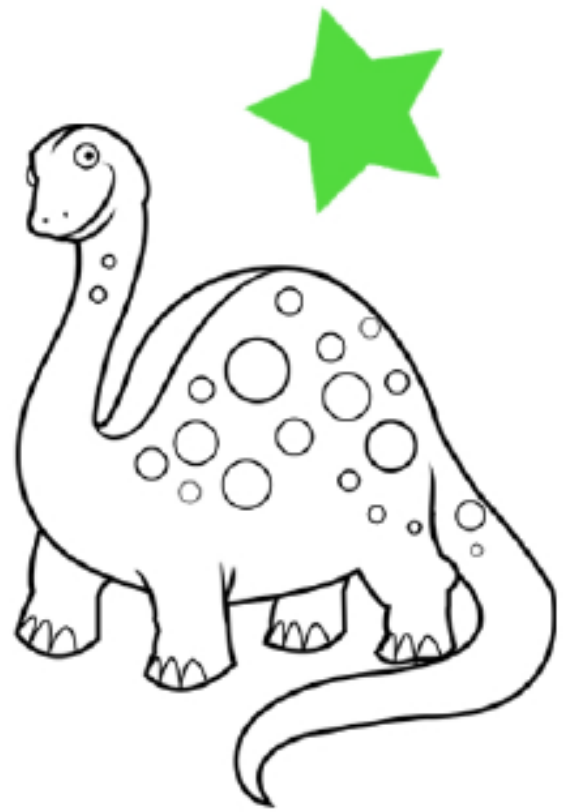

